\title{
Functional properties of a new spread based on olive oil and honeybees
}

\author{
Asma Tekiki ${ }^{1, *}$, Raoudha Helal ${ }^{2}$, Mnasser Hassouna ${ }^{1}$ and Salwa Bornaz ${ }^{1}$ \\ ${ }^{1}$ Research Unity "Food Sciences and Technology", High School of Food Industries of Tunis, \\ 58 Avenue Alain Savary, 1003, Tunis, Tunisia \\ ${ }^{2}$ Central Laboratory of Analysis and Essays of Tunis, 23, rue Jawaher Lel Nehru Montfleury,
}

1008Tunis, Tunisia

\begin{abstract}
A new alimentary concept has been developed since the 80's. This one is called "functional food". In this context, the olive oil and honey are traditionally used in their initial state as a basic food. They are considered as a potential source of new bioactive products from which we can formulate several functional foods. This work will focus on the elaboration of a new spread of honey and olive oil using beeswax as an emulsifier. Physicalchemical characterization, antioxidant and antibacterial activity were evaluated. As for the phenols content, spreads prepared from thyme honey has the highest content (337 mg GAE/kg) compared to other spreads. The antioxidant activity was evaluated by three different methods namely: DPPH test, ABTS + test and the iron reduction method (FRAP) which proves that this last has a higher activity than the other spreads $\left(\mathrm{EC}_{50} \mathrm{of} 70 \mathrm{mg}\right.$ /L using DPPH, $\mathrm{EC}_{50}$ of $20 \mathrm{mg} / \mathrm{L}$ using ABTS). An agar-well diffusion assay was used to assess the activity of honeys against seven bacteria strains. All prepared spreads honey samples showed highest antibacterial activity against all bacterial strains tested (diameter of ZI $>20 \mathrm{~mm}$ ). Hence, we note that our new spread proved by excellence to be a functional food due to the high content of phenols and the important antibacterial and antioxidant activities.
\end{abstract}

Keywords: honey; phenolic compounds; antioxidant activity; antibacterial activity; functional food

\section{Introduction}

Over the last few decades, consumer demands for food production have changed. Consumers believe more and more that foods have a direct impact on their health ${ }^{1,2}$. Today foods are not intended to satisfy the only hunger for humans but also to prevent nutritionrelated diseases and improve the physical and mental well-being of the human ${ }^{3,4}$.

Therefore, a new alimentary concept came to surface which is "Functional Food". This one is known for its benefits on health. These nutritional effects act as a stimulator for well being and decrease the risk of diseases. Any kind of food may be considered functional as soon as it provides benefits on one or more parts of the body organism ${ }^{4,5}$.

In addition to being used for therapeutic and medical purposes, honey is one of the most consumed foods in the world. The Codex Alimentarius defines honey as a natural sweet substance produced by the bees "Apis mellifera" from the nectar of the plants or from the secretions left on the parts of plants, which the bees forage, transform by combining them with *Corresponding author: Asma Tekiki

Email address: asma.tekiki@gmail.com

DOI: http://dx.doi.org/10.13171/mjc66/01801182226-tekiki specific substances Which they secrete, deposit, dehydrate, store and leave to refine and mature in the hive rays ${ }^{6}$. Besides, Honey has many medicinal effects such as antibacterial, hepatoprotective, hypoglycemic, reproductive, antihypertensive and antioxidant effects ${ }^{7}$. Beeswax (E901) is the natural wax produced by bees in the hive. It is used in cosmetics and skin care as a thickening agent, emulsifier, and a surfactant. Beeswax, however, is not valued in the food industry.

Olive oil is the main source of fat in the Mediterranean diet. It is much appreciated all over the world for its taste and aroma, as well as for its nutritional properties ${ }^{8}$. It's a functional food which besides of having a high level of monounsaturated fatty acid contains several minor components with bioactive properties such as the antioxidant phenolic compounds, squalene, and alpha-tocopherol. A large body of studies, either experimental or in animal models, have been performed to provide evidence that olive oil phenolic compounds contribute significantly to health benefits.

Received December 4, 2017 Accepted, January 9, 2018 Published January 18, 2018 
Olive oil and honey are traditionally used in their initial state as a basic food ${ }^{9}$. Indeed, thanks to their dietary, nutritional and functional interests ${ }^{9}$, these products deserve to be better valued and introduced into our alimentary diet. So, a combination of honey and olive oil may be very beneficial as the impact on human health will be huge. However, due to their potential source of a bioactive molecule, they may be envisaged on the bargain as the origin of a new kind of functional food.

Low-fat spreads are available in the market but with limited range. Characterizations of selected spreads from peanut butter, pistachio butter ${ }^{10}$, sesame, soy, and date ${ }^{11}$ are available. All these facts suggest the possibility of producing a functional lowfat spread from olive oil and honey. The aim of this work is the characterization of a spread based on olive oil and honey using beeswax as an emulsifier. Beeswax is used as an emulsifier to substitute chemical additives in order to have spread rich in nutrients as antioxidants and retaining the bioactive properties of honey and olive oil. The main goal of this work is to examine bioactive properties of the spread. Antibacterial activity was tested against seven bacteria; an agar-well diffusion assay was used. Three assays were used to screen the antioxidant properties (DPPH, ABTS, FRAP).

\section{Experimental}

\section{Samples}

The study was carried out on monovarietal virgin olive oil from the Tunisian cultivars, namely Chetoui, planted in the north of Tunisia. The honey samples were derived from eucalyptus, thyme and polyfloral origins which came from the north of Tunisia. Finally, natural beeswax sample was provided by the Central Laboratory for Analysis and Testing.

\section{Chemical reagents}

Barbituric acid, p-toluidine, Trolox and FolinCiocalteau reagent were purchased from SigmaAldrich (St. Louis, MO, USA); acetic acid, chloroform and methanol were purchased from Fluka Chemika (Buchs, Switzerland) of the highest purity available; 2.2 '-azinobis (3-ethylenbenzothiazoline-6sulfonic acid) (ABTS), 2,2-diphenyl-1-picrylhydrazyl (DPPH) radical were purchased from Merck (Darmstadt, Germany).

\section{Preparation of bread spreads}

Our bread spreads are made from $20 \%$ of olive oil which is melted with $1 \%$ beeswax in a water bath at $80{ }^{\circ} \mathrm{C}$. Once the emulsifier is liquefied $79 \%$ of honey is added. Homogenization of the mixture is carried out using a homogenizer (Ultraturax D-160 Homogenizer, Scilogex USA) by applying a speed of $15000 \mathrm{rpm}$ for 7 minutes. After production, each sample was transmitted in a hermetically sealed jar and stored at room temperature.

\section{Physicochemical analysis Stability test}

$15 \mathrm{~g}\left(\mathrm{~F}_{0}\right)$ of each sample was transferred to test tubes (internal diameter $30 \mathrm{~mm}$, height $500 \mathrm{~mm}$ ) which were tightly sealed with plastic caps and then centrifuged for $30 \mathrm{~min}$ at $5000 \mathrm{rpm}$ (Hettich, Roto silent/K, Germany). The weight of the precipitated fraction $\left(\mathrm{F}_{1}\right)$ was measured, and the emulsion stability was characterized as follows:

$$
\text { Stability }(\%)=\left(\mathbf{F}_{1} / \mathbf{F}_{0}\right) * 100
$$

Centrifugation was repeated three times to separate the oily fraction. Thus, the oily phase and the precipitate were recovered for the rest of analyses ${ }^{12}$.

\section{Peroxide value}

The peroxide value was determined for the oily phase of the spread. This index was carried out in accordance with ISO 3960: 2001. It's expressed in meq $\mathrm{O} 2$ / Kg body fat.

\section{Hydroxymethylfurfural (HMF) value}

The HMF value was determined for the honey to separate from the spread. First, $10 \mathrm{~g}$ of each sample was dissolved in $20 \mathrm{~mL}$ water; next, $2 \mathrm{~mL}$ of the solution was mixed with $5.0 \mathrm{~mL}$ of p-toluidine solution and put into two different test tubes. Last, 1 $\mathrm{mL}$ of distilled water (reference solution) was added into one tube; while to the second tube, $1 \mathrm{~mL}$ of barbituric acid solution $0.5 \%$ (sample solution) was added.

The absorbance of the solutions at $550 \mathrm{~nm}$ was determined using a spectrophotometer (ChromoTek $\mathrm{GmbH}$, Germany). The quantitative value of HMF was determined by using the proposed formula for the method ${ }^{13}$.

\section{Total phenolic content (TPC)}

The content of total phenol compounds was determined according to the method described by A. Boussaid et al. ${ }^{14} .1 \mathrm{~g}$ of sample (honey and spread) diluted with $10 \mathrm{~mL}$ of ultrapure water and filtered through a $45 \mathrm{~lm}$ Minisart filter. $0.5 \mathrm{~mL}$ of this solution was then mixed with $2.5 \mathrm{~mL}$ of Folin-Ciocalteu reagent $(0.2 \mathrm{~N})$ and $2 \mathrm{~mL}$ of sodium carbonate $(\mathrm{Na} 2$ CO 3) $(0.7 \mathrm{M})$ for $7 \mathrm{~min}$. After incubation in the dark at room temperature $\left(\approx 25^{\circ} \mathrm{C}\right.$. $)$ for $2 \mathrm{~h}$, the absorbance of the mixture was measured at $760 \mathrm{~nm}$ (spectrophotometer: ChromoTek GmbH, Germany). The total phenolic content was expressed in mg of gallic acid (equivalent mg GAE / Kg of honey).

\section{Antioxidant activity}

\section{DPPH radical scavenging assay}

The antioxidant activity of honey and spreads were studied by evaluating the free radical scavenging test (DPPH) as described by S. Ž Gorjanović et al. ${ }^{15}$. $1 \mathrm{~g}$ of each sample (honey, spreads) was dissolved in $1 \mathrm{~mL}$ of distilled water. A serial of four dilutions was done. 
Then, $200 \mu$ l of each concentration was mixed with $1800 \mu \mathrm{l}$ of methanol solution DPPH $(0.04 \mathrm{~g} / \mathrm{mL})$, incubation in dark for $30 \mathrm{~min}$. The absorbance of the reaction mixture was measured at $517 \mathrm{~nm}$ (spectrophotometer: ChromoTek GmbH, Germany).

Where:

$$
\text { DPPH }(\%)=\left(1-\frac{A x}{A 0}\right) \times 100
$$

$\mathrm{A}_{0}$ : absorbance of the control (distilled water).

$\mathrm{A}_{\mathrm{x}}$ : absorbance after reaction with honey or spread.

Results are expressed with EC50 using the serial dilution, which is the effective concentration of the sample at which $50 \%$ of initial amount of DPPH was scavenged. The Trolox was used as a standard.

\section{ABTS radical-scavenging assay:}

The ABTS assay was carried out according to the method of Re et al. (1999), partially improved by C. Cimpoiu et al. ${ }^{16}$. Radical scavenging activity was performed by mixing $100 \mu \mathrm{L}$ of the aqueous honey solution at different concentrations with $3 \mathrm{~mL}$ of ABTS $\bullet+$ solution. After 10 min of reaction in dark, the absorbance was read at $734 \mathrm{~nm}$ (spectrophotometer: ChromoTek GmbH, Germany). The blank used was $0.1 \mathrm{~mL}$ of aqueous honey solution mixed with $3.0 \mathrm{~mL}$ of distilled water.

The result was expressed by EC50 (mg/L) values determined as described previously in DPPH• assay. The Trolox was used as a standard.

\section{Ferric reducing power assay (FRAP)}

The principle of this method is based on the reduction of a ferric 2,4,6-tripyridyl-s-triazine complex (Fe3+-TPTZ) to its ferrous colored form (Fe2+-TPTZ) in the presence of antioxidants ${ }^{17}$. The $\mathrm{Fe} 3+$ reducing power of honey was determined by the method of G.C Yen ${ }^{18}$, with slight modifications by $\mathrm{H}$. A. Alzahrani et al. ${ }^{19}$. Honey $(2.5 \mathrm{~mL})$ was mixed with phosphate buffer $(2.5 \mathrm{~mL}, 0.2 \mathrm{M}, \mathrm{pH} 6.6)$ and $1 \%$ potassium ferricyanide $(2.5 \mathrm{~mL})$. The mixture was incubated for $20 \mathrm{~min}$ at $50{ }^{\circ} \mathrm{C}$. After incubation, $10 \%$ trichloroacetic acid $(2.5 \mathrm{~mL})$ was added to the mixtures, followed by centrifugation at $3000 \mathrm{rpm}$ for 10 min (Hettich, Roto silent/K, Germany). The upper layer $(1 \mathrm{~mL})$ was mixed with distilled water $(1 \mathrm{~mL})$ and $0.1 \%$ ferric chloride $(0.5 \mathrm{~mL})$. The absorbance of the obtained solution was measured at $700 \mathrm{~nm}$ (spectrophotometer: ChromoTek GmbH, Germany).

\section{Antibacterial activity}

Agar well diffusion was used for detection of antagonistic activity of each sample of honey and spread against 7 bacteria strains: E. coli (DH5a, IPT), $P$. aeruginosa (9027), Salmonella typhimurium (ATCC 09040726) and S. aureus (ATCC 25923), L. monocytogenes (ATCC 070101121), Klebsiella pneumonia (CIP104727) and Aeromonas hydrophila
(ATCC 7966). Preparation of the strain was done as described by $\mathrm{C}$. Basualdo et al. ${ }^{20}$. The concentration of cultures was $1 * 10^{7} \mathrm{CFU} / \mathrm{mL}$.

Honey and spreads solutions were prepared immediately before testing by diluting honey or spreads in sterilized water $10 \% \mathrm{v} / \mathrm{v}$. All samples were then incubated for 30 minutes at $37{ }^{\circ} \mathrm{C}$ in agitation. Fresh culture suspension of the test microorganisms $(100 \mu \mathrm{L})$ was spread on nutrient agar. Well, about 9 $\mathrm{mm}$ diameter was drilled on the culture after solidification media and $100 \mu \mathrm{l}$ of each honey dilution were added to each hole.

Plates were incubated at $37{ }^{\circ} \mathrm{C}$ for $24 \mathrm{~h}$, after which antagonistic activity was confirmed by the presence of a clear halo. Results were presented with ZDI (mm) the diameter of inhibition zone. ZDI is the mean of three replicates.

\section{Statistical analysis}

Statistical analysis and comparisons among means were carried out using the statistical package SPSS 17.0 (SPSS Inc., Chicago, IL.). Mean values of all data were obtained from the triplicate assay. The differences in mean values among samples were determined using one-way analysis of variance (ANOVA).

\section{Results and discussion}

Physical-chemical properties of the samples

Table 1 shows the physicochemical quality parameters of eight spreads studied. The most apparent problem of spreads is the tendency of the oil release. Using lipids with higher fluidness to produce spreads could affect the physical stability of the spreads; may significantly decrease the stability leading to oil release during storage ${ }^{21}$. This tendency to phase separation can be rapidly estimated by assessing the oil release from the spread upon centrifugation $^{22}$. Our spreads samples showed a high stability. Values of stability are in the range $97 \%$ and $98.8 \%$ there is no significant difference $(p<0.05)$ between samples. Moreover, the peroxide value of all the spreads was less than $\leq 20$ mequiv (limit accepted by Regulation COI/T.15/NC 2015). The peroxide value showed no significant difference $(p<0.05)$ between samples. The low index of peroxide value of prepared spreads proves the good fat quality of samples. For HMF (Hydroxymethylfurfural) value measured for all the samples are less than $40 \mathrm{mg} / \mathrm{kg}$ (limit value). The lowest HMF value was $1.25 \mathrm{mg} / \mathrm{kg}$ and $1.23 \mathrm{mg} / \mathrm{kg}$ measured for one sample eucalyptus spread and a sample of thyme spreads. This low value indicates that the sample is freshly extracted honey. This result was in agreement with that of I.N. Pasias et al. ${ }^{23}$, who confirmed that HMF content is below $10 \mathrm{mg} / \mathrm{Kg}$ in freshly honey. 
Table1. Physical-chemical property of parameters spreads.

\begin{tabular}{|l|l|l|l|}
\hline Samples & Stability \% & Peroxide Value meq $\mathrm{O}_{2} / \mathrm{Kg}$ & $\mathrm{HMF}$ value $\mathrm{mg} / \mathrm{kg}$ \\
\hline Polyfloral honey spread 1 & $97,73 \pm 0,35$ & $1,067 \pm 0,02$ & $25,6 \pm 0,6$ \\
\hline Polyfloral honey spread 2 & $97,267 \pm 0,31$ & $1,03 \pm 0,02$ & $30,97 \pm 0,21$ \\
\hline Eucalyptus honey spread 1 & $97,83 \pm 0,35$ & $0,95 \pm 0,08$ & $12,53 \pm 00,25$ \\
\hline Eucalyptus honey spread 2 & $98,03 \pm 0,6$ & $0,97 \pm 0,1$ & $19,36 \pm 0,56$ \\
\hline Eucalyptus honey spread 3 & $98,83 \pm 0,29$ & $1,46 \pm 0,3$ & $1,253 \pm 0,258$ \\
\hline Thyme honey spread 1 & $97,6 \pm 0,5$ & $1 \pm 0,03$ & $21,523 \pm 0,509$ \\
\hline Thyme honey spread 2 & $97,77 \pm 0,33$ & $1,01 \pm 0,09$ & $26,31 \pm 0,580$ \\
\hline Thyme honey spread 3 & $98,8 \pm 0,46$ & $1,42 \pm 0,26$ & $1,23 \pm 0,178$ \\
\hline
\end{tabular}

\section{Total phenolic content}

The results of the total phenolic content (TPC) of the eight Tunisian kinds of honey and eight spreads are shown in Table 2. TPC of honey ranged from 274 to $512 \mathrm{mg} \mathrm{GAE} / \mathrm{kg}$ honey. It was observed that the TPC showed significant differences among the different samples. The highest concentration of polyphenols was $512.8 \mathrm{mg} \mathrm{GAE} / \mathrm{kg}$ for sample honey thyme 3, while the lowest contents value was 201.27 $\mathrm{mg}$ GAE $/ \mathrm{kg}$ for polyfloral honey 2. The TPC of our Tunisian honey samples is in the same range of Algerian honeys ${ }^{24}$, Sundarban hneys 25 and Portuguese honey ${ }^{26}$. In addition, the TPC of the eight samples analyzed is higher than some Malaysian honey samples ${ }^{27}$ and Turkish honey samples ${ }^{28}$. For our eight prepared spreads, TPC values are between 183 and $337 \mathrm{mg}$ GAE/kg honey. Moreover, results showed that TPC values decreased significantly ( $\mathrm{p}<$ 0.05 ) while preparing the spread for all the eight samples of honey. Because spreads are composed only $79 \%$ of honey, it was observed the same ranking for spreads as for honey; the richest honey in phenol give the richest spread in phenol. Despite, this diminution of phenol in our spread, the TPC values remains important and higher than some Malaysian honey samples ${ }^{27}$ and Turkish honey samples ${ }^{28}$.

Table 2. Total phenol content (TPC) and antioxidants activities of honeys and spreads.

\begin{tabular}{|l|l|l|l|l|}
\hline \multicolumn{1}{|c|}{ Samples } & \multicolumn{1}{|c|}{ TPC $(\mathrm{mg} \mathrm{GAE} /$} & \multicolumn{1}{c|}{ EC50 DPPH value } & \multicolumn{1}{c|}{ EC50 ABTS value } & \multicolumn{1}{c|}{ EC50 FRAP } \\
\hline Polyfloral honey 1 & $274,3 \pm 12,2 \mathrm{~b}$ & $167 \pm 0,4 \mathrm{f}$ & $67 \pm 0,4 \mathrm{c}$ & $87 \pm 0,4 \mathrm{~d}$ \\
\hline Polyfloral honey 2 & $201,27 \pm 7,7 \mathrm{a}$ & $153 \pm 0,4 \mathrm{e}$ & $83 \pm 0,4 \mathrm{~d}$ & $103 \pm 0,4^{\mathrm{e}}$ \\
\hline Eucalyptus honey 1 & $402,8 \pm 6,6 \mathrm{c}$ & $90 \pm 0,1 \mathrm{~d}$ & $33 \pm 0,4 \mathrm{~b}$ & $65 \pm 0,7 \mathrm{~b}$ \\
\hline Eucalyptus honey 2 & $390,5 \pm 9,33 \mathrm{c}$ & $80 \pm 0,1 \mathrm{c}$ & $37 \pm 0,9 \mathrm{~b}$ & $73 \pm 0,4 \mathrm{c}$ \\
\hline Eucalyptus honey 3 & $410,1 \pm 7,33 \mathrm{c}$ & $77 \pm 0,4 \mathrm{c}$ & $33 \pm 0,4 \mathrm{~b}$ & $57 \pm 0,4 \mathrm{~b}$ \\
\hline Thyme honey 1 & $456,6 \pm 13,33 \mathrm{~d}$ & $40 \pm 0,1 \mathrm{~b}$ & $13 \pm 0,4 \mathrm{a}$ & $57 \pm 0,9 \mathrm{a}$ \\
\hline Thyme honey 2 & $479,5 \pm 9,33 \mathrm{~d}$ & $30 \pm 0,1 \mathrm{a}$ & $13 \pm 0,44 \mathrm{a}$ & $43 \pm 0,4 \mathrm{a}$ \\
\hline Thyme honey 3 & $512,8 \pm 8 \mathrm{e}$ & $23 \pm 0,4 \mathrm{a}$ & $12 \pm 0,4 \mathrm{a}$ & $37 \pm 0,4 \mathrm{a}$ \\
\hline Polyfloral honey spread 1 & $206,7 \pm 3,67$ & $199 \pm 0,7$ & $110 \pm 0,4$ & $92 \pm 0,8$ \\
\hline Polyfloral honey spread 2 & $183,6 \pm 3,2$ & $180 \pm 0,4$ & $110 \pm 0,7$ & $113 \pm 0,4$ \\
\hline Eucalyptus honey spread 1 & $261,8 \pm 2,94$ & $130 \pm 0,7$ & $46 \pm 0,3$ & $86 \pm 0,8$ \\
\hline Eucalyptus honey spread 2 & $224,9 \pm 2,933$ & $107 \pm 0,5$ & $50 \pm 0,5$ & $90 \pm 0,5$ \\
\hline Eucalyptus honey spread 3 & $229,5 \pm 4,27$ & $110 \pm 0,7$ & $60 \pm 0,7$ & $86 \pm 0,3$ \\
\hline Thyme honey spread 1 & $325 \pm 5,13$ & $82 \pm 0,5$ & $20 \pm 0,5$ & $45 \pm 0,4$ \\
\hline Thyme honey spread 2 & $330,2 \pm 3,9$ & $75 \pm 0,40$ & $20 \pm 0,2$ & $47 \pm 0,4$ \\
\hline Thyme honey spread 3 & $337,5 \pm 3,8$ & $70 \pm 0,3$ & $22 \pm 0,5$ & $42 \pm 0,5$ \\
\hline
\end{tabular}

Different letters in the same row indicate significantly different mean \pm standard deviation of triplicates $(p<0.05)$.

\section{Antioxidant activity}

The antioxidant activities were measured using three different spectrophotometric tests by scavenging radical DPPH', ABTS $\bullet+$ and reducing power FRAP. These are summarized in (Table2) and the results were expressed as $\mathrm{EC}_{50}$ values (milligram weight of sample per milliliter).

\section{DPPH• radical scavenging assay}

DPPH radicals measure the decrease in DPPH radical absorption after exposure to radical scavengers. While studying the radical-scavenging potential of honeys, the DPPH assay was frequently used because the antioxidant potential of honey has been correlated with its phenolic contents ${ }^{24,25}$. The DPPH radical scavenging activities of the eight honey samples (expressed by $\mathrm{EC}_{50}$ ) are shown in Table 2. Results showed that thyme honey samples were significantly $(\mathrm{p}<0.05)$ more active $\left(\mathrm{EC}_{50}\right.$ from 23 $\mathrm{mg} / \mathrm{mL}$ to $40 \mathrm{mg} / \mathrm{mL}$ ) than other honey samples $\left(\mathrm{EC}_{50}\right.$ from $77 \mathrm{mg} / \mathrm{mL}$ to $167 \mathrm{mg} / \mathrm{mL}$ ). Phenolic extracted from thyme honeys exhibited the higher content of phenols than those extracted from eucalyptus and polyfloral honeys (Table 2). Therefore, we can conclude that phenolic fraction could influence the 
antioxidant potential of each honey. Several studies showed that phenols present in honey affect the antioxidant capacity and free radical scavenging activity. The $\mathrm{EC}_{50}$ values measured in this study were similar and in the same range of some Algerian, Indian and Malaysian honeys ${ }^{29,30}$. The DPPH radical scavenging effect of honeys spreads prepared samples is also presented in Table 2. The $\mathrm{EC}_{50} \mathrm{DPPH}$ scavenging activity ranged from $70 \mathrm{mg} / \mathrm{mL}$ to 199 $\mathrm{mg} / \mathrm{mL}$. Besides, results showed that $\mathrm{EC}_{50} \mathrm{DPPH}$ scavenging values decreased significantly $(\mathrm{p}<0.05)$ while preparing the spread samples only for thyme honey. Spreads from eucalyptus and polyfloral honeys kept the same $\mathrm{EC}_{50}$ DPPH scavenging values than honeys. So, spreads present a good DPPH scavenging activity. Yet, the result showed that the antioxidant activity of honey and prepared spreads vary greatly depending on the honey's floral source.
ABTS $^{-+}$radical scavenging assay

ABTS activity was also quantified in terms of percentage inhibition $\left(\mathrm{EC}_{50}\right)$ of the ABTS $\bullet+$ radical cation of antioxidants in each honey sample. These two tests treat two different mechanisms of action using two different radicals (ABTS $\bullet+$ and DPPH ${ }^{31}$. It is for this reason that the two tests are not always well correlated and don't give the same results. Results in Table 2 showed a significant variation in the percentage inhibition of the honey samples, thyme honey was the most efficient scavenger of the radical (EC50 13mg/mL) followed by eucalyptus honeys, while polyfloral honey had the lowest scavenger inhibition effect (EC50 $67 \mathrm{mg} / \mathrm{mL}$ to $83 \mathrm{mg} / \mathrm{mL}$ ). This classification is similar to DPPH scavenging activity. As well, honeys have been shown to be a more effective scavenger of ABTS radical (Table 2).

Table 3. Diameter of inhibition zones ( $\mathrm{mm}$ ) produced by honeys and spreads on tested bacteria.

\begin{tabular}{|c|c|c|c|c|c|c|c|}
\hline Samples & S. arizonae & E. coli & S. aureus & $\begin{array}{l}P . \\
\text { aeruginosa }\end{array}$ & $\begin{array}{l}\text { A. } \\
\text { hydrophila }\end{array}$ & $\begin{array}{l}\text { L. } \\
\text { monocytogens }\end{array}$ & $\begin{array}{l}\text { K. } \\
\text { pneumonie }\end{array}$ \\
\hline Polyfloral honey 1 & $28,33 \pm 0,44$ & $27 \pm 0,67$ & $30,33 \pm 0,44$ & $25,33 \pm 0,44$ & $23,33 \pm 0,44$ & $23,33 \pm 0,66$ & $25,33 \pm 0,44$ \\
\hline Polyfloral honey 2 & $22,67 \pm 8,89$ & $30 \pm 0,44$ & $24,33 \pm 0,44$ & $27,33 \pm 0,44$ & $22,33 \pm 0,44$ & $20,33 \pm 0,44$ & $24,33 \pm 0,44$ \\
\hline Eucalyptus honey 1 & $30,3 \pm 0,44$ & $33,44 \pm 0,44$ & $29 \pm 0,67$ & $35,33 \pm 0,44$ & $34,33 \pm 0,44$ & $30,33 \pm 1,33$ & $30,33 \pm 0,44$ \\
\hline Eucalyptus honey 2 & $23 \pm 13,3$ & $30,33 \pm 0,44$ & $31,33 \pm 0,44$ & $31,33 \pm 0,44$ & $29,33 \pm 0,44$ & $30,33 \pm 0,44$ & $31,33 \pm 0,44$ \\
\hline Eucalyptus honey 3 & $30,3 \pm 0,44$ & $36,33 \pm 0,44$ & $30,66 \pm 0,44$ & $34,33 \pm 0,44$ & $33,33 \pm 0,44$ & $30,33 \pm 0$ & $29,33 \pm 0,44$ \\
\hline Thyme honey 1 & $22,67 \pm 13,1$ & $31 \pm 0,67$ & $32,33 \pm 0,44$ & $30,33 \pm 0,44$ & $28,33 \pm 0,44$ & $29,33 \pm 0,44$ & $28 \pm 0$ \\
\hline Thyme honey 2 & $31,67 \pm 0,44$ & $30,33 \pm 0,44$ & $28,33 \pm 0,44$ & $30,33 \pm 0,44$ & $32,33 \pm 0,44$ & $3167 \pm 0,89$ & $27,33 \pm 0,44$ \\
\hline Thyme honey 3 & $38,67 \pm 0,44$ & $35,33 \pm 0,44$ & $29,33 \pm 0,44$ & $28,33 \pm 0,44$ & $31,33 \pm 0,44$ & $29 \pm 0,67$ & $31 \pm 1,33$ \\
\hline $\begin{array}{l}\text { Polyfloral honey } \\
\text { spread } 1\end{array}$ & $25 \pm 0,67$ & $29,33 \pm 0,44$ & $28,67 \pm 0,44$ & $28,67 \pm 0,44$ & $21,67 \pm 0,44$ & $24,67 \pm 0,44$ & $24 \pm 0$ \\
\hline $\begin{array}{l}\text { Polyfloral honey } \\
\text { spread } 2\end{array}$ & $25,33 \pm 0,44$ & $27,33 \pm 0,44$ & $26,33 \pm 0,44$ & $26,67 \pm 0,4$ & $23,33 \pm 0,44$ & $21,33 \pm 0,44$ & $24,33 \pm 0,89$ \\
\hline $\begin{array}{l}\text { Eucalyptus honey } \\
\text { spread } 1\end{array}$ & $29,33 \pm 0,44$ & $31,67 \pm 0,44$ & $32,67 \pm 0,44$ & $30,67 \pm 0,44$ & $31 \pm 0,67$ & $27,33 \pm 0,44$ & $30,33 \pm 0,44$ \\
\hline $\begin{array}{l}\text { Eucalyptus honey } \\
\text { spread } 2\end{array}$ & $30,67 \pm 0,44$ & $31,33 \pm 0,44$ & $29,33 \pm 0,44$ & $26,67 \pm 0,44$ & $32,67 \pm 0,44$ & $29,67 \pm 0,89$ & $32 \pm 0,67$ \\
\hline $\begin{array}{l}\text { Eucalyptus honey } \\
\text { spread } 3\end{array}$ & $28,33 \pm 0,44$ & $33,33 \pm 0,44$ & $30,33 \pm 0,44$ & $27,67 \pm 0,44$ & $30,33 \pm 0,44$ & $30 \pm 0,667$ & $30,33 \pm 0,44$ \\
\hline Thyme honey spread 1 & $30 \pm 0$ & $29,67 \pm 0,44$ & $32 \pm 0$ & $29,33 \pm 0,44$ & $29,33 \pm 0,44$ & $28,33 \pm 0,889$ & $28,33 \pm 0,44$ \\
\hline Thyme honey spread 2 & $29,33 \pm 0,44$ & $30,67 \pm 0,44$ & $28 \pm 0,67$ & $27,67 \pm 0,88$ & $30,67 \pm 0,44$ & $27 \pm 0,667$ & $26,67 \pm 0,89$ \\
\hline Thyme honey spread 3 & $32,33 \pm 0,44$ & $32,67 \pm 0,44$ & $29,33 \pm 0,44$ & $27,67 \pm 0,44$ & $30,33 \pm 0,44$ & $29,67 \pm 0,89$ & $30 \pm 0,67$ \\
\hline
\end{tabular}

These results could be explained by the nature of phenolic compounds present in honeys which can react with $\mathrm{ABTS} \bullet+$ better than $\mathrm{DPPH} \bullet$. The $\mathrm{EC}_{50}$ values of spread prepared range from $12 \mathrm{mg} / \mathrm{mL}$ to $110 \mathrm{mg} / \mathrm{mL}$, showing significant differences $(\mathrm{p}<0.05)$ and keeping the same classification as honeys samples. Using ABTS activity, thyme honeys and prepared thyme honeys don't show significant differences $(p<0.05)$ conversely of the result showed with DPPH radical. 


\section{FRAP assay}

Reducing power is another important parameter for the evaluation of antioxidant activity. The FRAP assay measured the ability of honey samples to reduce $\mathrm{Fe}$ (III) to $\mathrm{Fe}$ (II) in an acidic medium ${ }^{31}$. Based on the results of the FRAP assay in Table 2, we detected a significant difference $(\mathrm{p}<0.05)$ between the honey samples. As shown, thyme honey samples were roughly three times more active than eucalyptus and polyfloral honey samples. The eight prepared spreads showed $50 \%$ reduction at $37 \mathrm{mg} / \mathrm{mL}$ to $113 \mathrm{mg} / \mathrm{mL}$ with significant differences $(\mathrm{p}<0.05)$ between samples. In FRAP assay, only prepared eucalyptus spread showed significant differences $(p<0.05)$ with eucalyptus honey samples.

To summarize, the eight tested honey samples and the spreads prepared showed high antioxidant activity. In addition, we can say that spreads kept the same antioxidant levels as honeys.

\section{Antibacterial activity}

The results of the inhibition tests ran with honey samples and honey spreads on the bacterial strains used in this study are shown in Table 3 (Diameter ZI mm). The antibacterial activity was classified as: no sensitive, for diameters lower than 8 $\mathrm{mm}$; sensitive, for diameters from 8 to $14 \mathrm{~mm}$; very sensitive, for diameters from 15 to $19 \mathrm{~mm}$; extremely sensitive, for diameters higher than $20 \mathrm{~mm}^{32}$. The results revealed that the eight samples of honey and their prepared spreads showed an excellent antibacterial activity, all diameter of ZI is more than $20 \mathrm{~mm}$. Salmonella arizonae and Staphylococcus aureus was the most sensitive strains against honeys samples and spreads. No single honey exhibited exceptional inhibitory activity than other honeys or spreads. The antibacterial activity of honey is related to several factors acting alone or in synergy. The most prominent of them are hydrogen peroxide, phenolic compounds, the $\mathrm{pH}$ of honey and the osmotic pressure exerted by honey ${ }^{32,33}$. Hydrogen peroxide is the major inhibitor substance of honey. Concentration values of this compound in different honeys result in their varying antimicrobial effects ${ }^{33,34}$.

\section{Conclusion}

From the above results, we can conclude the possibility to formulate a functional spread based on olive oil and honeybee emulsified by beeswax. The physicochemical parameters (Stability, IP, HMF) give us information about the quality of the prepared spreads and their aptitude of conservation due to the low obtained values of peroxide and HMF. The high content of phenol and the strong bacterial, as well as antioxidant activities, makes from our new spread an important and interesting product for consumers who are currently looking for foods rich in bioactive properties.

\section{Acknowledgments}

This work was supported by grants from The Institution for Research and Higher Education in Agriculture (Ministry of Agriculture, Tunisia) and Central Laboratory of Analysis and Testing of Tunis.

\section{References}

1- B. Mollet, I. Rowland. Current Opinion in Biotechnology 2012, 13, 483-485.

2- Bui Duy Tung. Eurasian J of Business and Economics 2015, 8(16), 19-34.

3- B. V da Silva, J.CM Barreira, M. Beatriz P.P Oliveiza, Trends in food science and technology, 2016, (50) 144-158.

4- F. S Reis, A. Martins, M.H Vasconcelos, P. Morales, I.C.F.R. Fereira. Trends in food science and technology, 2017, (66) 48-62.

5- E.C. Robert. Wildman Handbook of Nutraceuticals and Functional Foods, Second Edition, ed. By Taylor Francis group LLC 2007, pp 2-5.

6- Codex Alimentarius Commission. Revised Codex Standard for honey 2003, Codex STAN 12-1981, Rev. 1 (1987), Rev. 2 (2001).

7- O. Erejuwa, A.S Siti, Ab Wahab, Molecules, 2012, 17(4), 4400-4423. https://doi.org/10.3390/molecules 17044400.

8- C. A Ballus, A. D. Meinhart, F. A. de Souza Campos, L. F de Olivera da Silva, F.A. de Oliveira, H. T Godoy. Food Research International (2014)., 62, 74-83.

9- B.Y. Sheikh, M. M.R Sarker, M.N.A Kamarudin, A. Ismail. Biomedicine \& Pharmacotherapy 2017, (95) 614-648.

10- M. Mousazadeh, M. Mousavi, Z.E Djomeh, M. Hadinezadeh, S.M. Taghi Ghirbzahedi. Int. J. Food Prop. 2014, (17), 1355-1368.

11- P. Taylor, S.M.A Razavi, H.Karazhiyan. Int J of Food Properties 2013, 37-41.

12- V. Nikzade, M. Mazaheri Tehrani, M. Saadatmand-Tarzjan, Food Hydrocolloids 2012, (28) 344-352.

13- M.I. Khalil, S.A. Sulaiman S.H. Gan. Food and Chemical Toxicology 2010, (48) 2388-2392.

14- A. Boussaid, M.Chouaibi, L. Rezig, R. Hellal, F. Donsì, G. Ferrari, S. Hamdi. Arabian Journal of Chemistry.2014. https://doi.org/10.1016/j.arabjc.2014.08.011.

15- S. Ž Gorjanović, J. M.Alvarez-Suarez, M.M. Novaković, F.T.Pastor, L.Pezo, M. Battino, D. Ž. Sužnjević. J of Food Composition and Analysis, 2013, 30(1), 13-18. https://doi.org/10.1016/j.jfca.2012.12.004.

16- C. Cimpoiu, A.Hosu, V. Miclaus, A. Puscas. Spectrochimica Acta Part A: Molecular and Biomolecular Spectroscopy, 2013, 100, 149154. https://doi.org/10.1016/j.saa.2012.04.008. 
17- A.M. de Almeida, M. B. S. Oliveira, J.G. da Costa, I.B. Valentim, M.O. F. Goularta. Rev. Virtual Quim., 2016, 8 (1), 57-77.

18- G.C Yen, P.D Duh. J. Am. Oil Chem. Soc. 1993, 70, 383-386.

19- H. A. Alzahrani, R. Alsabehi, L. Boukraâ, F. Abdellah, Y. Bellik, B.A. Bakhotmah. Molecules, 2012, 17(9), 10540-10549. https://doi.org/10.3390/molecules170910540.

20- C. Basualdo, V. Sgroy, M.S Finola, J.M. Marioli. Veterinary Microbiology, (2007). 124(3-4), 375-381. https://doi.org/10.1016/j.vetmic.2007.04.039.

21- M. Mousazadeh, S. M. Mousavi, Z. EmamDjomeh, M. HadiNezhad, N. Rahmati. Int J of Biological Macromolecules, (2013). 56, 133-139. https://doi.org/10.1016/j.ijbiomac.2013.02.001.

22- L. Manzocco, S. Calligaris, M. Camerin, L. Pizzale, M.C Nicoli. Jof Food Engineering, 2014, 126, 120-125. https://doi.org/10.1016/j.jfoodeng.2013.10.042.

23- I.N. Pasias, I.K. Kiriakou, C. Proestos. Food Chemistry, 2017, (229), 425-431.

24- M. I. Khalil, M. Moniruzzaman, L. Boukraâ, M. Benhanifia, M.A. Islam, M.N. Islam, S.H. Gan. Molecules, 2012, 17(9), 11199-11215. https://doi.org/10.3390/molecules170911199.
25- R. Afroz, E.M. Tanvir, S. Paul, N.C. Bhoumik, S.Hua Gan, M.I Khalil. Journal of Food Biochemistry 2016, 40, 436-445.

26- I. C. F. R. Ferreira, E. Aires, J. C. M. Barreira, L.M. Estevinho. Food Chemistry, 2009, 114(4), 1438-1443.

27- M.I. Khalil, N. Alam, M. Moniruzzaman, S.A. Sulaiman, S.H. Gan . J. Food Science, 2011, 76(6), 921-928.

28- Z. Can, O. Yildiz, H. Sahin, E. Akyuz Turumtay, S. Silici, S. Kolayli. Food Chemistry, 2015, 180, 133-141.

29- S. Saxena, S. Gautam, Sharma, Food Chem. 2010, 118, 391-397.

30- M.I Khalil, M. Mahaneem, S.M.S. Jamalullail, N. Alam, S.A Sulaiman. J. ApiProd. ApiMedi. Sci., 2011, 3, 4-11.

31- L. Müller, K. Fröhlich, V. Böhm. J Food Chem., 2011, (129) 139-148.

32- A. Moussa, N. Djebeli, M. Abdelmelek, A. Saad. Asian Pacific Journal of Tropical Disease, 2012, 2(3), 211-214. https://doi.org/10.1016/S2222-1808(12)60048$\underline{6 .}$

33- $\bar{N}$. Roshan, T. Rippers, C. Locher, K. A. Hammer. Arch Microbiol., 2017, 199, 347-355.

34- T.H. Ayaad, G.H Shaker, A.M. Almuhnaa. J of King Saud University Science. 2012, 24, 193-200. 